\title{
Experimental campaign on the upgraded He-FUS3 facility
}

\author{
Gianluca Barone ${ }^{\mathrm{a}}$, Daniele Martelli ${ }^{\mathrm{a}}$, Nicola Forgione ${ }^{\mathrm{a}}$, Marco Utili ${ }^{\mathrm{b}}$, Italo Ricapito ${ }^{\mathrm{c}}$ \\ ${ }^{a}$ University of Pisa, Department of Civil and Industrial Engineering (DICI), Largo Lucio Lazzarino 2, 56122 Pisa, Italy \\ ${ }^{b}$ ENEA UTIS-TCI, CR Brasimone, Camugnano, Italy \\ TBM\&MD Project, Fusion for Energy, EU Commission, Carrer J. Pla, 2, Building B3, 08019 Barcelona, Spain $^{c}$
}

\begin{abstract}
An extensive thermal-hydraulic experimental campaign was conducted on He-FUS3 helium loop facility to support the conceptual design of HCLL and HCPB Test Blanket System. The experiments were divided into three distinct phases. The first one was dedicated to the evaluation of the new ATEKO Turbo Circulator (TC) performances, identifying its operating limits in terms of supplied helium mass flow as a function of rotational speed, cold by-pass opening and loop pressure. The outcomes were compared with the manufacturer theoretical performance map and with a RELAP5-3D pre-test computation. In the second phase, experiments were carried out to analyze the facility dynamic response in hot conditions and to characterize its main components $(T C$, heaters, economizer, cooling system and valves). The wide amount of collected data will serve for the development and validation of a numerical model of the facility at TBS conditions. For the third phase, the tests were designed to investigate He-FUS3 behavior in accidental conditions representative of LOFAs and LOCAs scenarios.
\end{abstract}

Keywords: He-FUS3, HCS, LOCA, LOFA, RELAP

\section{Introduction}

The F4E-FPA-372 $1^{\text {st }}$ Specific Grant [1] deals with experimental activities in support of the Conceptual Design of HCLL and HCPB Test Blanket Systems. In particular, Service-2 is focused on thermal-hydraulic tests with high pressure helium for validation and benchmarking of suitable dedicated numerical tools. The Service is split into tasks, three of which involved the HeFUS3 facility [2, 3]. He-FUS3 (see Figure 1) is a helium experimental system designed and realized by ENEA to test the thermal-mechanical properties of prototypical module assemblies of the DEMO reactor. The actual facility was upgraded with a high-performance compressor and an additional water cooling system that integrated the pre-existent Air Cooler [4]. In addition, a new Test Section (TS), located in the loop hot zone, was settled down to investigate safety relevant transient conditions of an "In-TBM" LOCA scenario. An experimental campaign was executed to extensively investigate the upgraded facility behavior and to provide, inter alia, a valuable database for system code V\&V purposes. The experiments were performed for a wide range of operative conditions including incidental scenarios (LOFA and LOCA). The outcomes of the experimental campaign are reported and discussed in the present paper.

\section{He-FUS3 Experimental campaign}

\subsection{Turbo circulator performance map}

A first series of tests were conducted to characterize the Turbo Circulator (TC) [5] operating region on the theoretical performance map $(P M)$ for the upgraded HeFUS3 configuration. This region was experimentally evaluated in steady state cold conditions for three different pressures $(60,70$ and 80 bar) and for different rotational speeds (from 15000 to $38000 \mathrm{rpm}$ ), hence, different helium flows. For each $T C$ speed, the effect of the cold bypass $(B P)$ was evaluated, by gradually (stepwise) opening its $1 / 2$ " valve, FV-235, from $0 \%$ (fully closed) to $100 \%$ (fully opened). The operating points are defined by the corrected mass flow rate $(C M F$, in abscissa) [5] and the pressure ratio $\left(P R=p_{\text {out }} / p_{\text {in }}\right.$, in ordinate), both values were directly provided by the $T C$ control panel. 
This is the Author's Generated Preprint of an article published in Fusion Engineering and Design and available online at the following link:

https://doi.org/10.1016/i.fusengdes.2017.02.046

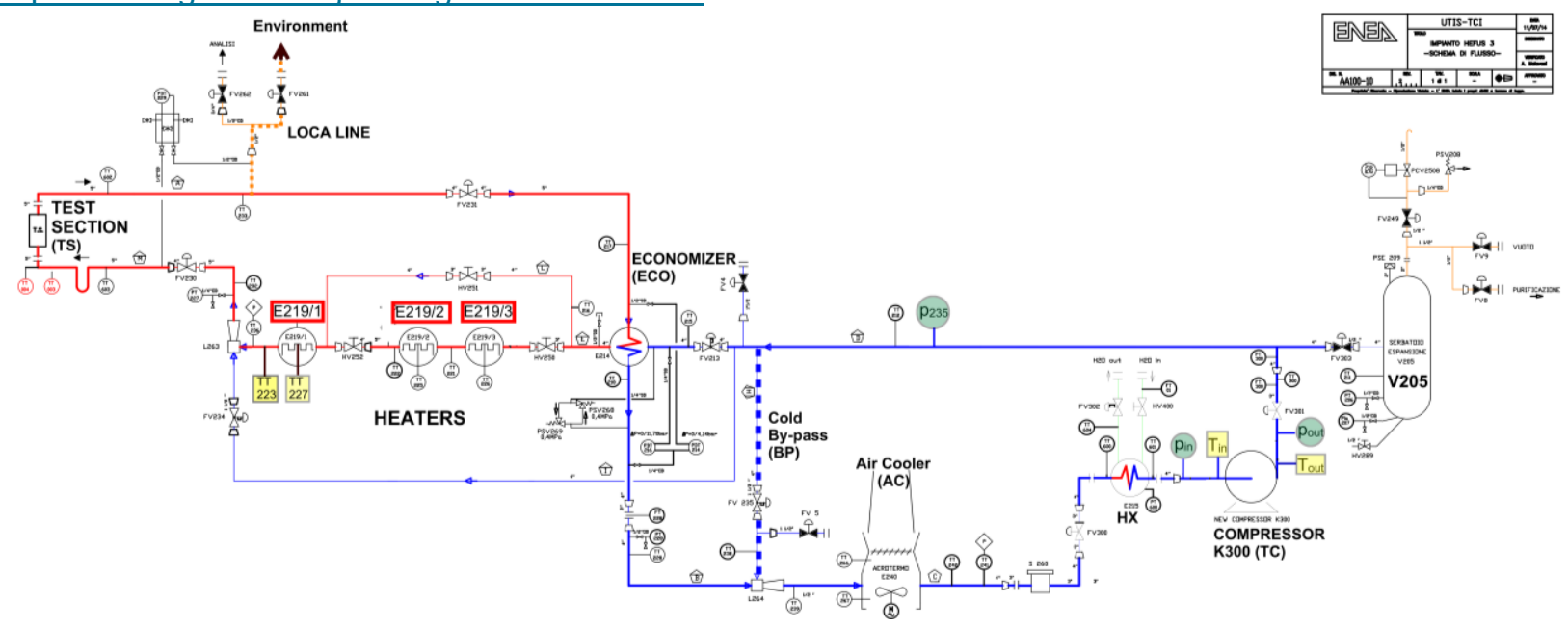

Fig. 1. He-FUS3 P\&ID.

Referring to the test at 80 bar, Figure 2 shows the trend of the $T C$ velocity (progressively reduced) and the resulting flow rate (total, to $T S$ and to the $B P$ ) varying with the $B P$ valve position. An increase of the total flow can be observed when the $B P$ opened. In Figure 3 the $T C$ inlet and outlet pressures $\left(p_{\text {in }}\right.$ and $\left.p_{\text {out }}\right)$ and temperatures $\left(T_{\text {in }}\right.$ and $T_{\text {out }}$ ) are reported. The cooling system (Air Cooler or water $H X$ ) was activated to cool the helium (after the compression) to the design $T_{i n}$, around $50^{\circ} \mathrm{C}$.

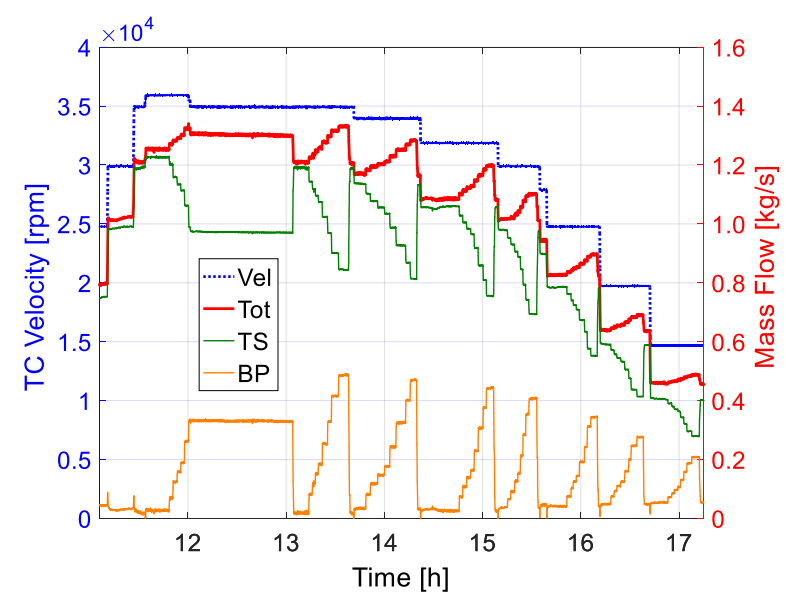

Fig. 2. $T C$ vel. and flows trends (cold, 80 bar).

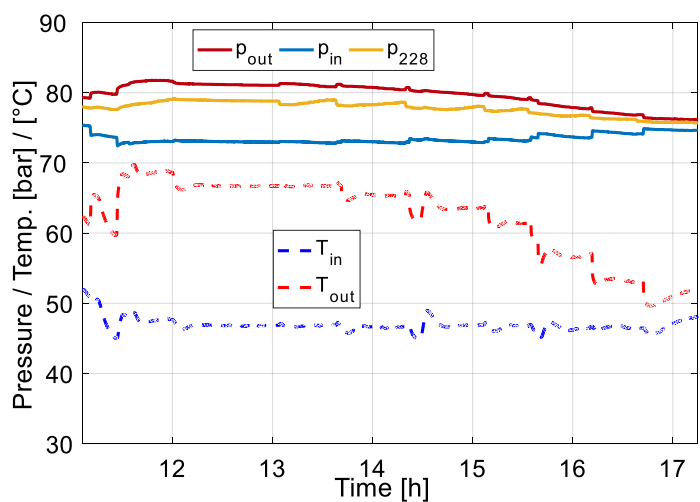

Fig 3. Pressures and TC temperatures trends (cold, 80 bar).

With the $B P$ valve FV235 completely closed, the total mass flow ranges from $0.46 \mathrm{~kg} / \mathrm{s}(15000 \mathrm{rpm})$ to $1.26 \mathrm{~kg} / \mathrm{s}$ (36000 rpm). At $36000 \mathrm{rpm}$, the full valve opening causes a total flow increase up to $1.33 \mathrm{~kg} / \mathrm{s}$ while the $T S$ flow results about $1 \mathrm{~kg} / \mathrm{s}$. In Table 1 the main parameters for the 80 bar test are resumed.

Table 1. Cold test main parameters, $(80 \mathrm{bar})$.

\begin{tabular}{llc}
\hline Parameter & Unit & Range of values \\
\hline$p_{\text {out }}$ & bar & $77-82$ \\
TC speed & rpm & $15-36000$ \\
TC current & $\mathrm{A}$ & $254-520$ \\
TC head & bar & $1.54-8.72$ \\
Tot. flow & $\mathrm{kg} / \mathrm{s}$ & $0.46-1.33$ \\
TS $/$ Tot & $\%$ & (BP open) $70-(\mathrm{BP}$ close) 98 \\
$T_{\text {in }}$ & ${ }^{\circ} \mathrm{C}$ & $\sim 47$ \\
$T_{\text {out }}$ & ${ }^{\circ} \mathrm{C}$ & $50-70$ \\
\hline
\end{tabular}

In Figure 4 the experimental outcomes are reported and compared with the theoretical $T C$ performance map provided by the manufacturer. The resulting $T C$ operating region can be identified (in yellow) between the points with the $B P$ completely opened and completely closed.

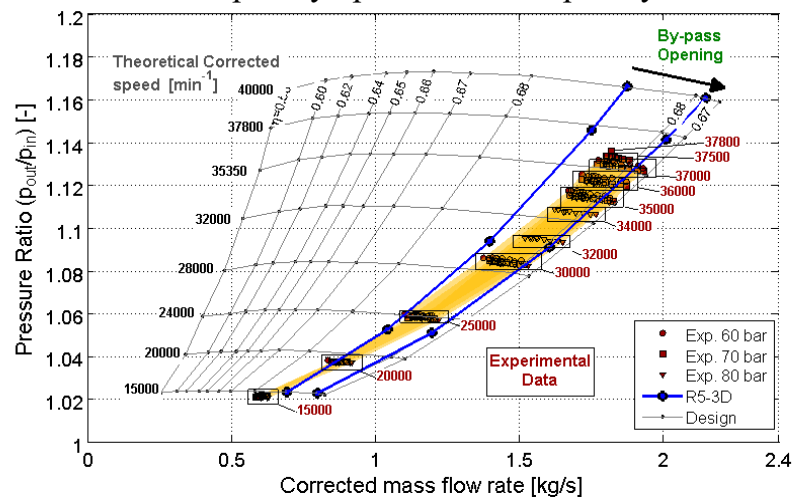

Fig. 4. TC operating region and $\mathrm{R} 5-3 \mathrm{D}$ results.

For a given $T C$ velocity, the $B P$ valve opening (or closing) causes the shift of the operating point rightward (or leftward) due to the change in the helium flow distribution through the loop. The BP opening "gives breath" to the $T C$ by reducing the loop hydraulic resistance with a consequent increase (about 10\%) of the total flow. The $B P$ opening entails a reduction of the $T S$ flow to $65-70 \%$ of the total. The experimental data observed for a given $T C$ velocity are found to be below the corresponding theoretical iso-velocity curves, especially for higher velocities. This discrepancy is visible also from the RELAP5-3D pre-test assessment [6] as the TC modelling was based on the theoretical data. Nevertheless, the pre- 
This is the Author's Generated Preprint of an article published in Fusion Engineering and Design and available online at the following link:

\section{https://doi.org/10.1016/j.fusengdes.2017.02.046}

test numerical simulations (blue lines curves) give a quite good prediction of the operating region. The operating region extent for the current upgraded loop is reduced compared to the previous configuration [7]. In fact, the upgrade involved a reduction in the circuit hydraulic resistances, making the cold $B P$ worth less marked.

\subsection{Test Blanket System conditions experiments}

These "hot" tests aimed at generating a database for the development and validation of a He-FUS3 RELAP5-3D numerical model at TBS conditions. The experiments were conducted in ITER relevant configurations and operative conditions. The three heaters were activated at their maximum power (total of $210 \mathrm{~kW}$ ) to heat up the helium flowing through the TS. The helium cooling, to the imposed $T C$ inlet temperature (below $55^{\circ} \mathrm{C}$ ), was assured by the water HX. The tests reference helium pressures were 60,70 and 80 bar. For each pressure, two conditions were investigated:

H1. The maximum TS helium flow in "hot" conditions and the corresponding $T S$ temperature. The $T C$ operated at its highest velocity ( $B P$ valve closed).

H2. The helium $T S$ flow needed to reach a stationary TS temperature around $500^{\circ} \mathrm{C}$. The $T C$ operated at a moderate speed ( $B P$ valve opened).

Therefore, a total of six tests were executed and the facility performances were assessed. Referring to the hot conditions at 60 bar, the main outcomes are depicted in the following two plots. Figure 5 reports the $T C$ velocity trend (and the $B P$ opening) with the loop mass flow, while Figure 6 reports the loop temperatures and pressures. The experiment started at $\mathrm{t}=8 \mathrm{~h}$, from a stationary state characterized by a $T C$ velocity of $30000 \mathrm{rpm}$, a TC outlet pressure $\left(p_{\text {out }}\right)$ of 54 bar and a TS temperature of $370^{\circ} \mathrm{C}$.

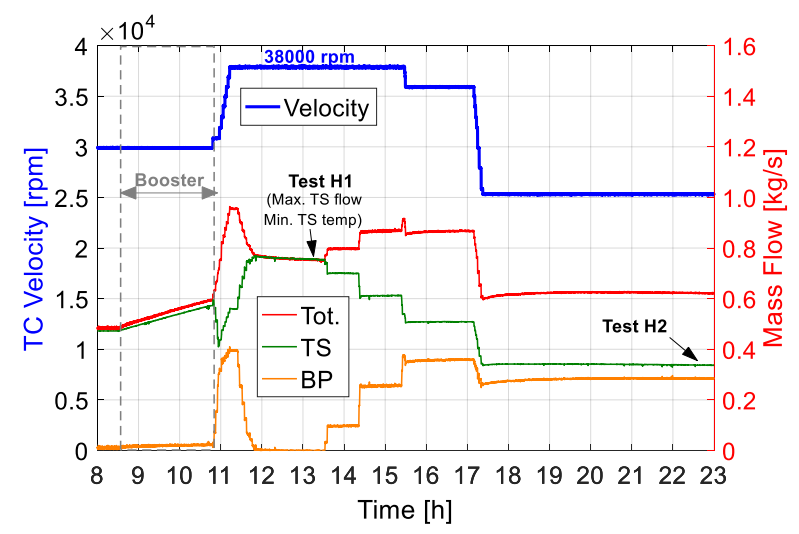

Fig. 5. TC vel. and flows trends (hot, 60 bar).

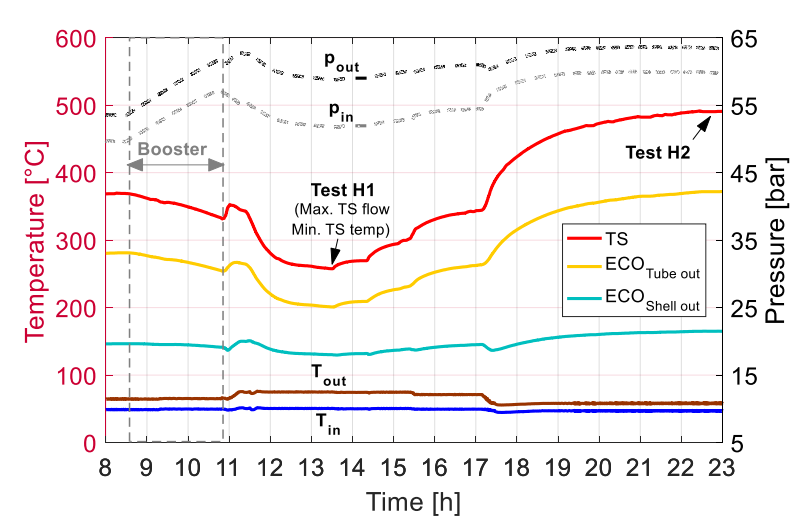

Fig. 6. $T C$ vel. and flow trends (hot, 60 bar).

From this condition, the loop was pressurized to reach a pressure of about 62 bar via a booster system from the storage tank V205. Then, the $T C$ velocity was gradually increased up to $38000 \mathrm{rpm}$ (maximum $T C$ velocity) and, at the same time, the $B P$ valve was opened to reduce the onset of $T C$ axial elongation oscillation that could have led to an emergency shut-down of the $T C$. Once reached a stable state, the valve was closed again. Test H1 was characterized by a maximum $T S$ helium flow of about $0.76 \mathrm{~kg} / \mathrm{s}$ and a $T S$ stationary temperature of about $255^{\circ} \mathrm{C}$ (reached at $\mathrm{t}=13.5 \mathrm{~h}$ ). Then, test $\mathrm{H} 2$ started by completely opening the $B P$ valve and decreasing the $T C$ velocity to $25000 \mathrm{rpm}(\mathrm{t}=17.3 \mathrm{~h})$. The test gave a $T S$ mass flow rate equal to $0.34 \mathrm{~kg} / \mathrm{s}$ and a stationary $T S$ temperature around $490^{\circ} \mathrm{C}(\mathrm{t}=23 \mathrm{~h})$. The following tests, at 70 and 80 bar, were conducted in the same manner.

Regarding the experiments at 80 bar, test $\mathrm{H} 1$ stationary conditions were achieved for a $T C$ velocity of $36000 \mathrm{rpm}$ (limited by the maximum TC current of $505 \mathrm{~A}$ ) and closing the valve FV235. The resulting TS maximum temperature was around $177^{\circ} \mathrm{C}$ with $T S$ mass flow rate of about $1.18 \mathrm{~kg} / \mathrm{s}$. Afterward, to reach the conditions for test $\mathrm{H} 2$, valve FV235 was completely opened and the $T C$ velocity was reduced to $15000 \mathrm{rpm}$ providing a $T S$ mass flow rate of about $0.3 \mathrm{~kg} / \mathrm{s}$. At this point, temperatures and pressures increased monotonically for the next 3 hours. As the pressure was increasing too much, it was necessary to discharge some helium from the loop in order not to exceed the loop pressure limit ( 85 bar). The test was stopped due the occurrence of a major leakage that caused an important loop depressurization despite the helium temperature continued to increase. At this time, the $T S$ temperature reached $450^{\circ} \mathrm{C}$. In Table 2, the main parameters acquired during tests $\mathrm{H} 1$ and $\mathrm{H} 2$ are compared for the reference pressures of 60 and 80 bar.

Table 2. Parameters of the TBS experiments (60 vs. 80 bar).

\begin{tabular}{lccc}
\hline Parameter & Unit & \multicolumn{2}{c}{ Range of values $(\mathbf{H 1 + H 2 )}$} \\
\hline Ref. press. & bar & 60 & 80 \\
\hline Heat Pwr. & $\mathrm{kW}$ & 210 & 210 \\
ECO Pwr. & $\mathrm{kW}$ & $500-575$ & $433-510$ \\
ECO Eff. & $\%$ & $70-75$ & $66-75$ \\
\hline TC p $_{\text {out }}$ & $\mathrm{bar}$ & $59-63$ & $78-82$ \\
TC speed & $\mathrm{rpm}$ & $25-38 \cdot 10^{3}$ & $15-36 \cdot 10^{3}$ \\
TC head & bar & $3.7-7.4$ & $1.6-8.6$ \\
\hline
\end{tabular}


This is the Author's Generated Preprint of an article published in Fusion Engineering and Design and available online at the following link:

\begin{tabular}{lccc}
\multicolumn{4}{c}{ https://doi.org/10.1016/j.fusengdes.2017.02.046 } \\
\hline Tot. flow & $\mathrm{kg} / \mathrm{s}$ & $0.62-0.95$ & $0.52-1.38$ \\
TS flow & $\mathrm{kg} / \mathrm{s}$ & $0.34-0.76$ & $0.30-1.22$ \\
TS T $^{\text {max }}$ & ${ }^{\circ} \mathrm{C}$ & $495-255$ & $450-177$ \\
\hline
\end{tabular}

The pressure trend in hot conditions was affected by the $T C$ velocity, the facility hot zone temperature (major effect) and the helium leakages. The helium leakages, negligible in the cold tests, in this hot experimental phase were found to be slightly higher. However, they did not affect the validity of the experiment as far as the loop pressure fell within the range of interest.

\subsection{Accidental transients: LOFA and LOCA Tests}

The campaign was completed with a series of experiments designed to characterize He-FUS3 in abnormal conditions representative of HCS LOFAs and LOCAs scenarios.

\subsubsection{Loss of flow experiment}

To execute the LOFA test the facility was brought in stationary hot $(210 \mathrm{~kW})$ conditions characterized by a loop pressure of about 80 bar, the $B P$ valve FV235 closed and a $T C$ rotational velocity of $35000 \mathrm{rpm}$, providing a total and $T S$ flow of about 1.35 and $1.3 \mathrm{~kg} / \mathrm{s}$, respectively. From this state, the LOFA was simulated by shutting down the $T C$ in a safe mode (linear velocity decrease). In Figure 7 the transient evolution is described.

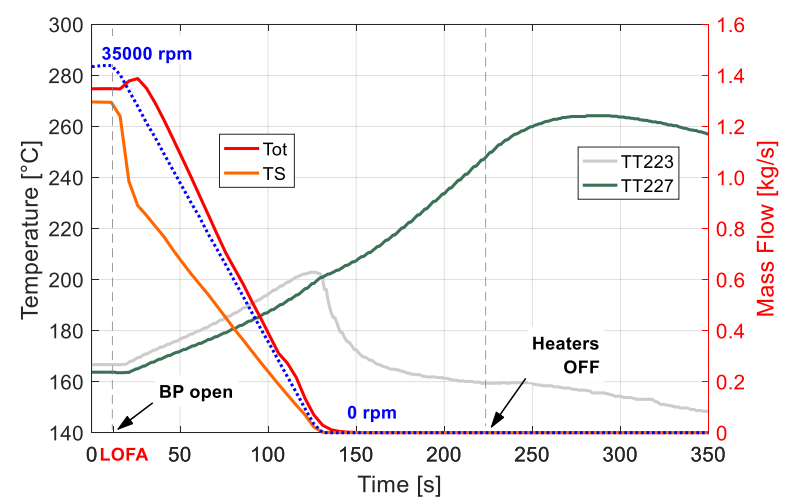

Fig. 7. $T C$ vel., flow and temp. trends (LOFA, 80 bar).

The $T C$ and therefore the loop total helium flow stopped in about $120 \mathrm{~s}$, the latter following the same $T C$ velocity linear decrease. A steeper decrease of the flow through the $T S$ (and heaters) occurred immediately after the $T C$ shut down due to the automatic $B P$ valve opening. Thermocouples TT223 and TT227, measuring the temperatures inside and downstream the third heater E219/1, were monitored; T227 was assumed as the TS temperature. These temperatures showed a steady state value of $165^{\circ} \mathrm{C}$ which was the initial maximum loop temperature for the experimental conditions. The two temperatures started to increase as the LOFA took place (due to the flow decreasing). TT223 increased as long as helium flowed through the heaters ( $T C$ running), after which, it started to decrease. TT227 continued to increase even in absence of flow, being located inside the heater. At $\mathrm{t}=220 \mathrm{~s}$, the heaters were shut down but TT227 continued to rise for about $50 \mathrm{~s}$ (due to the heating elements thermal inertia) to a maximum of $263^{\circ} \mathrm{C}$ and then decreased. The overall temperature jump for TT227 was about $100^{\circ} \mathrm{C}$.

\subsubsection{Loss of coolant experiment}

The LOCA experiment was conducted to reproduce an "In-TBM" LOCA accidental event. The test took place with heaters at full power $(210 \mathrm{~kW})$ from a loop stationary condition with a reference pressure, $p_{2}$, around 82 bar and a $T C$ speed of $35000 \mathrm{rpm}$ providing a total and $T S$ flow rate of 1.39 and $1.34 \mathrm{~kg} / \mathrm{s}$ respectively. The third heaters thermocouples TT223 (downstream E219\1) and TT227 (inside E219/1) measured a steady state value around $160^{\circ} \mathrm{C}$. The LOCA took place opening the isolation valve FV261 that isolates the TS "In-TBM" LOCA line from the environment. The blowdown through a $2 \cdot 10^{-5} \mathrm{~m}^{2}$ nozzle lasted about $450 \mathrm{~s}$. The loop pressures and hot temperatures trend are reported in Figure 8.

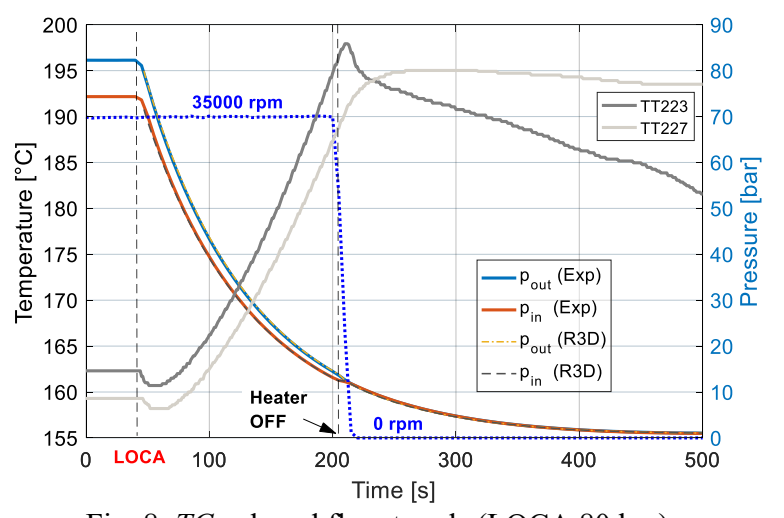

Fig. 8. $T C$ vel. and flow trends (LOCA,80 bar).

The $T C$ continued to operate during the transient until the loop pressure reached 13.5 bar; then the $T C$ protection system automatically shut down the machine and, simultaneously, the three heaters were deactivated. The helium flow decreased following the depressurization trend as long as the $T C$ was operating (at a constant velocity of $35000 \mathrm{rpm}$ ), while, after the $T C$ stopped, a steep decrease to zero was observed. TT223 and TT227 temperature trend showed an initial decrease (a few ${ }^{\circ} \mathrm{C}$ ) due to the pressure rapid reduction, followed by an increase caused by the flow reduction through the heaters. For TT223, the temperature increased till the heaters shut down and then started to decrease; for TT227 the decrease after the heaters shut down is more gradual because of the thermal inertia of the heating elements. Referring to TT223, a temperature jump of $37^{\circ} \mathrm{C}$ (max. temperature of $198^{\circ} \mathrm{C}$ ) is observed in about $180 \mathrm{~s}$. A RELAP5-3D posttest assessment was performed to reproduce the LOCA test showing an optimal agreement of the simulated depressurization with the experimental trend (see Figure 8).

\section{Conclusions}

The TC operating region for the upgraded He-FUS3 layout was experimentally generated, in cold conditions (reference pressures of 60, 70 and 80 bar), varying the $T C$ velocity (from 15000 to $38000 \mathrm{rpm}$ ) and the $B P$ valve opening. The comparison with the theoretical performance map showed discrepancies for higher $T C$ velocities. Accordingly, adjustments are required in the RELAP5-3D compressor model (based on the theoretical data) employed in the numerical pre-test simulations. 
This is the Author's Generated Preprint of an article published in Fusion Engineering and Design and available online at the following link:

https://doi.org/10.1016/j.fusengdes.2017.02.046

Nevertheless, the pre-test simulation outcomes showed a qualitatively sufficient prediction of the experimental $T C$ operating region. The next series of experiments was devoted to analyze the system in hot conditions by activating the three heaters $(210 \mathrm{~kW})$. The maximum total and $T S$ flow were evaluated for each reference pressure with the relative $T S$ maximum temperature. At 80 bar the maximum $T S$ flow and temperature were $1.22 \mathrm{~kg} / \mathrm{s}$ and $177^{\circ} \mathrm{C}$ respectively. A $T S$ mass flow of about $0.35 \mathrm{~kg} / \mathrm{s}$ was needed to obtain a maximum temperature of about $500^{\circ} \mathrm{C}$. In the third experimental phase, accidental scenarios were investigated, namely, a LOFA and a LOCA tests were reproduced to investigate the corresponding loop pressure and temperature evolution. The loop depressurization during the LOCA was simulated by RELAP5-3D showing a very precise reproduction of the pressure trends. In conclusion, the experimental campaign provided an accurate assessment of the overall facility dynamic response for a wide range of operating conditions. Moreover, the outcomes will constitute an extensive and valuable database for the system numerical model validation.

\section{Acknowledgments}

The work leading to this publication has been partially funded by Fusion for Energy under the specific grant FPA-372-SG01. The views and opinions expressed herein do not necessarily reflect those of F4E nor those of the ITER Organization. Special thanks go to our F4E Colleagues and to ENEA Brasimone Colleague Andrea Malavasi.

\section{References}

[1] M. Utili, "F4E-FPA-372: SG01. (Deliverable 2D01), Specific Grant 01 of Framework Partnership Agreement F4E-FPA-372”, May 2014.

[2] G. Dell'Orco, "He-FUS 3, European Cooled Blanket Test Facility for DEMO", ENEA Report DM3ING.DOC, 9/7/1996.

[3] Ansaldo, "Impianto He-FUS3: Manuale operativo".

[4] A. Tincani, G. Coccoluto, G. Lamma, S. Nucci, G. Polazzi, L. Rapezzi, I. Sacchetti, "Upgrading of the He-FUS3 helium loop for testing TBMs".

[5] ATEKO - P.Schustr, J. Zach, J. Klepal, "TurboCirculators EFDA, Studies Rev. 3.2”, December 2007.

[6] G. Barone et al., "Development of a model for the thermalhydraulic characterization of the He-FUS3 loop", Fusion Engineering and Design 96-97 (2015) 212-216.

[7] ATEKO “Acceptance test of the TC No.01", 23/08/2010. 